\title{
Specialty Grand Challenge: Multi-Criteria Decision Making for Better Sustainability
}

\author{
Jingzheng Ren* \\ Department of Industrial and Systems Engineering, The Hong Kong Polytechnic University, Hong Kong, China
}

Keywords: sustainability, multi-criteria decision analysis, multi-criteria decision making, life cycle assessment, life cycle sustainability assessment

\section{INTRODUCTION}

Sustainable development defined by the World Commission on Environment and Development in 1987 refers to "Development that meets the needs of the present without compromising the ability of future generations to meet their own needs." (UNWCED, 1987). The United Nations proposed a set of global Sustainable Development Goals (SDGs) with 17 goals and 169 targets in March 2015 (Hák et al., 2016). Accordingly, it is apparent that sustainability or sustainable development usually emphasizes on the factors and criteria in multiple dimensions. The most popular way for measuring sustainability is the so-called Triple Bottom Line (TBL) framework which can incorporate profit, people and the planet simultaneously, and it aims to encourage the stakeholders/decision-makers to achieve sustainable development with the considerations of not only the individual's profits but also people's live and the planet (Hacking and Guthrie, 2008). Therefore, the concept of sustainability usually consists of three pillars: economic prosperity, environmental cleanness, and social responsibility (Liu and Huang, 2012). Some scholars also pointed out that sustainability or sustainable development should also incorporate some other dimensions (i.e., technological, policy and political aspects, etc.), because the factors in technological, policy, and political dimensions can significant influence the factors in the three main pillars of sustainability (Ren et al., 2016). For instance, energy efficiency and exergy efficiency in technological dimension have significant impact on economic performances and environmental impacts. To some extent, higher energy efficiency and exergy efficiency means more profits and less emissions. It could be concluded that sustainability or sustainable development is a multi-dimensional concept. In other words, multiple factors/criteria are usually prerequisite to be incorporated in the decisions related to sustainability, namely, the so-called "multi-criteria decision making (MCDM)." Multi-criteria decision making, also called "multi-criteria decision analysis" refers to the evaluation of multiple conflicting criteria in decision making, and it usually involves multiple decision criteria and multiple alternatives. MCDM has become a powerful tool for sustainability issues, including (1) sustainability assessment and analysis; (2) sustainability ranking and prioritization; (3) sustainability enhancement and improvement; and (4) sustainability design and optimization. However, there are still various challenges in these four fields.

\section{SUSTAINABILITY ASSESSMENT AND ANALYSIS}

Sustainability assessment and analysis usually include economic, environmental and social sustainability assessment, and life cycle tools including life cycle assessment (LCA), life cycle costing (LCC), and social life cycle assessment (SLCA) are usually employed to investigate the environmental impacts (i.e., global warming potential and acidification potential), economic performances (i.e., life cycle cost, net present value and internal return of rate, etc.) and social 
issues (i.e., social acceptability, work environment and impacts on local culture, etc.) of different alternatives (Ren et al., 2015). Life cycle sustainability assessment (LCSA) as the combination of LCA, LCC, and SLCA has also be widely used for multi-criteria sustainability assessment and analysis. However, there are still various challenges (Ren, 2018a; Ren et al., 2018): (i) how to quantify the "soft" criteria (i.e., social acceptability, work environment, and technology maturity, etc.), especially the criteria in social aspect for sustainability assessment? (ii) how to aggregate the multiple criteria for sustainability assessment into one composite or aggregated index which can represents the overall life cycle sustainability of each alternative? and (iii) how to measure the life cycle performances in technological, policy, and policy dimensions accurately?

\section{SUSTAINABILITY RANKING AND PRIORITIZATION}

After life cycle sustainability assessment and analysis of different alternatives, it is still difficult for the decisionmakers/stakeholders to select the most sustainable alternative among multiple choices, because there are usually various conflict criteria, and one alterative performs better with respect to several criteria, but may performance worse with respect to some other criteria. For instance, the alternative A has less global warming potential and acidification potential comparing with $\mathrm{B}$, but $\mathrm{A}$ has higher life cycle cost and lower social acceptability. Therefore, the stakeholders/decision-makers are puzzled to an important question: which one is more sustainable or the most sustainable? The combinations of LCSA and MCDM have been widely used for sustainability ranking and prioritization (Ren, 2018b). LCSA+MCDM can effectively help the stakeholders/decision-makers to prioritize the alternatives from life cycle sustainability perspective with the considerations of the preferences of the stakeholders/decision-makers. LCSA+MCDM for sustainability ranking and prioritization usually consists of three main steps: (i) employing LCSA to obtain the data of the alternatives with respect to the criteria for life cycle sustainability assessment; (ii) determining the weights of the criteria for life cycle sustainability assessment; and (iii) using MCDM to rank the alternatives. However, there are still various challenges in life cycle sustainability ranking and prioritization: (i) how to handle the uncertainties including both aleatory uncertainty and epistemic uncertainty (Liu and Huang, 2012) in sustainability ranking and prioritization? (ii) there are usually various groups of decision-makers/stakeholders with different opinions and preferences involved in the process of sustainability ranking and prioritization, how to incorporate the preferences of different decision-makers in the decision-making process? and (iii) how to make informed decision under hybrid information? Besides the uncertainties, it is usually difficult for the users to quantify the "soft" criteria for sustainability assessment, and the linguistic terms or fuzzy sets are usually used to depict the relative performances of the alternatives with respect to these "soft" criteria, thus, the decision-making matrix usually consists of hybrid information rather than only crisp numbers.

\section{SUSTAINABILITY ENHANCEMENT AND IMPROVEMENT}

Sustainability enhancement and improvement aims to enhance or improve the sustainability performances of the existing alternative or systems with appropriate technologies. There are various factors/criteria influencing the sustainability performances of the alternatives, and these factors/criteria are not independent but usually interacted and independent. It is usually difficult for the stakeholders/decision-makers to identify the complex cause-effect relationships among these factors/criteria. Accordingly, it is prerequisite to identify the complex cause-effect relationships for obtaining the critical "causes" leading to bad sustainability performances. There are various qualitative methods that can be used for sustainability enhancement and improvement by identifying the main "causes" leading to bad sustainability such as fishbone diagram (Lin et al., 2019) and DPSIR (drivers, pressures, state, impact, and response) (Carr et al., 2007) model for describing the interactions among factors/criteria of sustainability. Besides these qualitative methods, there are also various semi-qualitative and semi-quantitative methods that can be used for identifying the cause-effect relationships among the factor/criteria influencing sustainability such as decision-making trial and evaluation laboratory (DEMATEL) and analytic network process (ANP) as well as various improved DEMATEL and ANP methods (i.e., fuzzy DEMATEL, fuzzy ANP, gray DEMATEL, gray ANP, intuitionistic fuzzy DEMATEL, and intuitionistic fuzzy ANP, etc.) (Ren et al., 2013; Mehregan et al., 2014). There are also some emerging quantitative models for sustainability enhancement and improvement such as the mathematical framework for optimal process sustainability performance enhancement with the considerations of economic, environmental, social, and technical feasibilities (Moradi-Aliabadi and Huang, 2016), the decision support framework for sustainability enhancement based on the two-layered hierarchical control scheme (Moradi-Aliabadi and Huang, 2018), and the combination of vector-based multiattribute decision-making method and weighted multiobjective optimization technique ( $\mathrm{Xu}$ et al., 2019). However, there are still various challenges in life cycle sustainability enhancement and improvement: (i) how to incorporate the requirements (sustainability objectives) of the stakeholders in the model for sustainability enhancement and improvement? (ii) how to develop systematic model for making informed decisions on sustainability enhancement and improvement from life cycle sustainability perspective? and (iii) how to develop the generic models for sustainability enhancement and improved that can be used in different scales (process, plant, enterprise, municipal, provincial, and national scales)? 


\section{SUSTAINABILITY DESIGN AND OPTIMIZATION}

Sustainability design and optimization refers to developing mathematical models to achieve sustainable design and optimization of industrial systems at the early-design stage. The most popular models are all about sustainability-oriented design and optimization of supply chain in process industries, and there are various models in the previously studies, i.e., goal programming model (Zhou et al., 2000), multiobjective evolutionary optimization model (Zhang et al., 2014), robust multi-objective optimization model (Majewski et al., 2017), and MINLP model (Yue and You, 2013). All these models about sustainability design and optimization usually consider not only the economic objectives but also the environmental and social objectives, and various uncertainties are also incorporated in these models. However, there are still various challenges in sustainability design and optimization: (i) these optimization models cannot incorporate as many sustainability objectives/criteria as that used in sustainability ranking and prioritization. And most of the models consider three or $<3$ objectives. How to incorporate a complete list of sustainability objectives/criteria in the optimization model? (ii) how to handle the various uncertainties in the models for sustainability design and optimization? and (iii) how to determine subjectoriented model which can incorporate the requirements of

\section{REFERENCES}

Carr, E. R., Wingard, P. M., Yorty, S. C., Thompson, M. C., Jensen, N. K., and Roberson, J. (2007). Applying DPSIR to sustainable development. Int. J. Sustain. Develop World Ecol. 14, 543-555. doi: 10.1080/13504500709469753

Hacking, T., and Guthrie, P. (2008). A framework for clarifying the meaning of triple bottom-line, integrated, and sustainability assessment. Environ. Impact Assess.Rev. 28, 73-89. doi: 10.1016/j.eiar.2007.03.002

Hák, T., Janoušková, S., and Moldan, B. (2016). Sustainable development goals: a need for relevant indicators. Ecol. Indicat. 60, 565-573. doi: 10.1016/j.ecolind.2015.08.003

Lin, R., Liu, Y., Man, Y., and Ren, J. (2019). Towards a sustainable distributed energy system in China: decision-making for strategies and policy implications. Energy Sustain. Soc. 9, 1-25. doi: 10.1186/s13705-019-0237-9

Liu, Z., and Huang, Y. (2012). Technology evaluation and decision making for sustainability enhancement of industrial systems under uncertainty. AIChE J. 58, 1841-1852. doi: 10.1002/aic.13818

Majewski, D. E., Wirtz, M., Lampe, M., and Bardow, A. (2017). Robust multi-objective optimization for sustainable design of distributed energy supply systems. Comput. Chem. Eng. 102, 26-39. doi: 10.1016/j.compchemeng.2016.11.038

Mehregan, M. R., Hashemi, S. H., Karimi, A., and Merikhi, B. (2014). Analysis of interactions among sustainability supplier selection criteria using ISM and fuzzy DEMATEL. Int. J. Appl. Decision Sci. 7, 270-294. doi: 10.1504/IJADS.2014.063226

Moradi-Aliabadi, M., and Huang, Y. (2016). Multistage optimization for chemical process sustainability enhancement under uncertainty. ACS Sustain. Chem. Eng. 4, 6133-6143. doi: 10.1021/acssuschemeng.6b01601

Moradi-Aliabadi, M., and Huang, Y. (2018). Decision support for enhancement of manufacturing sustainability: a hierarchical control approach. ACS Sustain. Chem. Eng. 6, 4809-4820. doi: 10.1021/acssuschemeng.7b04090 the decision-makers/stakeholders for sustainability design and optimization.

\section{FUTURE RESEARCH FOCUS AND CHALLENGES}

The overall goal of Frontiers of Sustainability|Multi-criteria Decision Making is to present various sustainability-oriented decision-making methods, and the future research of this specialty will continuously focus on (1) sustainability assessment and analysis; (2) sustainability ranking and prioritization; (3) sustainability enhancement and improvement; and (4) sustainability design and optimization. And the following conditions will also be incorporated in these sustainabilityoriented decision-making methods:

※ Multi-dimensional

※ Multi-stakeholder

※ Multi-objective

※ Multi-scenario

※ulti-scale

※ Multi-level.

\section{AUTHOR CONTRIBUTIONS}

The author confirms being the sole contributor of this work and has approved it for publication.

Ren, J. (2018a). Life cycle aggregated sustainability index for the prioritization of industrial systems under data uncertainties. Comput. Chem. Eng. 113, 253-263. doi: 10.1016/j.compchemeng.2018.03.015

Ren, J. (2018b). Multi-criteria decision making for the prioritization of energy systems under uncertainties after life cycle sustainability assessment. Sustain. Product. Consump. 16, 45-57. doi: 10.1016/j.spc.2018. 06.005

Ren, J., Manzardo, A., Mazzi, A., Zuliani, F., and Scipioni, A. (2015). Prioritization of bioethanol production pathways in China based on life cycle sustainability assessment and multicriteria decisionmaking. Int. J. Life Cycle Assess. 20, 842-853. doi: 10.1007/s11367-0150877-8

Ren, J., Manzardo, A., Toniolo, S., and Scipioni, A. (2013). Sustainability of hydrogen supply chain. Part I: identification of critical criteria and causeeffect analysis for enhancing the sustainability using DEMATEL. Int. J. Hydrogen Energy 38, 14159-14171. doi: 10.1016/j.ijhydene.2013. 08.126

Ren, J., Ren, X., Dong, L., Manzardo, A., He, C., and Pan, M. (2018). Multiactor multicriteria decision making for life cycle sustainability assessment under uncertainties. AIChE J. 64, 2103-2112. doi: 10.1002/aic.16149

Ren, J., Xu, D., Cao, H., Wei, S. A., Dong, L., and Goodsite, M. E. (2016). Sustainability decision support framework for industrial system prioritization. AIChE J. 62, 108-130. doi: 10.1002/aic. 15039

United Nations World Commission on Environment and Development (UNWCED) (1987). Our Common Future. The Brundtland Report.

Xu, D., Li, W., Shen, W., and Dong, L. (2019). Decision-making for sustainability enhancement of chemical systems under uncertainties: combining the vector-based multiattribute decision-making method with weighted multiobjective optimization technique. Industrial Eng. Chem. Res. 58, 12066-12079. doi: 10.1021/acs.iecr.9b01531 
Yue, D., and You, F. (2013). Sustainable scheduling of batch processes under economic and environmental criteria with MINLP models and algorithms. Comput. Chem. Eng. 54, 44-59. doi: 10.1016/j.compchemeng.2013.03.013

Zhang, W., Wang, C., Li, Y., Wang, P., Wang, Q., and Wang, D. (2014). Seeking sustainability: multiobjective evolutionary optimization for urban wastewater reuse in China. Environ. Sci. Technol. 48, 1094-1102. doi: 10.1021/es404082f

Zhou, Z., Cheng, S., and Hua, B. (2000). Supply chain optimization of continuous process industries with sustainability considerations. Comput. Chem. Eng. 24, 1151-1158. doi: 10.1016/S0098-1354(00)00496-8
Conflict of Interest: The author declares that the research was conducted in the absence of any commercial or financial relationships that could be construed as a potential conflict of interest.

Copyright $\odot 2020$ Ren. This is an open-access article distributed under the terms of the Creative Commons Attribution License (CC BY). The use, distribution or reproduction in other forums is permitted, provided the original author(s) and the copyright owner(s) are credited and that the original publication in this journal is cited, in accordance with accepted academic practice. No use, distribution or reproduction is permitted which does not comply with these terms. 